\title{
Malaria vectors in South America: current and future scenarios
}

\author{
Gabriel Zorello Laporta ${ }^{1,2,3^{*}}$, Yvonne-Marie Linton ${ }^{4,5,6,7}$, Richard C. Wilkerson ${ }^{4,5,6}$, Eduardo Sterlino Bergo ${ }^{8}$,
} Sandra Sayuri Nagaki ${ }^{1}$, Denise Cristina Sant'Ana ${ }^{1}$ and Maria Anice Mureb Sallum ${ }^{1}$

\begin{abstract}
Background: Malaria remains a significant public health issue in South America. Future climate change may influence the distribution of the disease, which is dependent on the distribution of those Anopheles mosquitoes competent to transmit Plasmodium falciparum. Herein, predictive niche models of the habitat suitability for $P$. falciparum, the current primary vector Anopheles darlingi and nine other known and/or potential vector species of the Neotropical Albitarsis Complex, were used to document the current situation and project future scenarios under climate changes in South America in 2070.

Methods: To build each ecological niche model, we employed topography, climate and biome, and the currently defined distribution of P. falciparum, An. darlingi and nine species comprising the Albitarsis Complex in South America. Current and future (i.e., 2070) distributions were forecast by projecting the fitted ecological niche model onto the current environmental situation and two scenarios of simulated climate change. Statistical analyses were performed between the parasite and each vector in both the present and future scenarios to address potential vector roles in the dynamics of malaria transmission.
\end{abstract}

Results: Current distributions of malaria vector species were associated with that of $P$. falciparum, confirming their role in transmission, especially An. darlingi, An. marajoara and An. deaneorum. Projected climate changes included higher temperatures, lower water availability and biome modifications. Regardless of future scenarios considered, the geographic distribution of $P$. falciparum was exacerbated in 2070 South America, with the distribution of the pathogen covering 35-46\% of the continent. As the current primary vector An. darlingi showed low tolerance for drier environments, the projected climate change would significantly reduce suitable habitat, impacting both its distribution and abundance. Conversely, climate generalist members of the Albitarsis Complex showed significant spatial and temporal expansion potential in 2070, and we conclude these species will become more important in the dynamics of malaria transmission in South America.

Conclusions: Our data suggest that climate and landscape effects will elevate the importance of members of the Albitarsis Complex in malaria transmission in South America in 2070, highlighting the need for further studies addressing the bionomics, ecology and behaviours of the species comprising the Albitarsis Complex.

Keywords: Anopheles darlingi, Albitarsis Complex, Climate change, Ecological niche model, Plasmodium falciparum

\footnotetext{
* Correspondence: gabrielzorelo@usp.br

'Departamento de Epidemiologia, Faculdade de Saúde Pública, Universidade de São Paulo, São Paulo, SP, Brazil

2Laboratório de Informática Médica, Faculdade de Medicina, Universidade de São Paulo, São Paulo, SP, Brazil

Full list of author information is available at the end of the article
} 


\section{Background}

Current consensus among scientists is that global patterns of climate warming observed over the past twenty years are attributable to human activities [1-3], and public statements endorsing this position have been issued by scientific organizations worldwide [4, 5]. Some health-related issues of humans and animals are correlated to climate change, including heat-related disorders, respiratory disorders, vector-borne diseases, water-borne diseases, food insecurity, and mental health disorders that are associated with natural disasters [6].

The epidemiology of vector-borne diseases has been under the influence of climate change at the global level since the last quarter of the 20th Century [7]. Consequently, the impact of climate factors on malaria reemergence or emergence has attracted considerable attention in studies relating climate factors to mosquito ecology $[8$, 9]. This particular interest reflects the fact that malaria is a significant public health burden and, concomitantly, the dynamics of transmission are highly sensitive to environmental conditions [10, 11]. Additionally, the future distribution of malaria is dependent on the distribution of competent Anopheles vectors, especially those that are exophagic climate generalists [12].

In Brazil, the number of malaria cases attributable to $P$. falciparum is decreasing annually, mainly because of the successful control and elimination strategies adopted by the Malaria Control Program [13]. In 2012, P. falciparum accounted for only $10 \%$ out of 276,000 confirmed malaria cases [14]. Anopheles darlingi Root is the primary malaria vector in South America, transmitting both $P$. falciparum and $P$. vivax in Brazil $[15,16]$, but many other species are also involved in the dynamics of the transmission of Plasmodium [17]. These include members of the Albitarsis Complex that have attracted attention because of the high number of new species described in recent years [18-22]. The Albitarsis Complex comprises five formally described species (An. albitarsis Lynch Arribalzaga, An. deaneorum Rosa-Freitas, An. janconnae Wilkerson and Sallum, An. marajoara Galvao and Damasceno, An. oryzalimnetes Wilkerson and Motoki), and three recognized unnamed species, An. albitarsis F [20], An. albitarsis G [21, 22], An. albitarsis I [22] [20-24]. Anopheles albitarsis $\mathrm{H}$ was originally conservatively described as a mitochondrial lineage due to low sample size [22], but has since been more widely detected and should be considered a separate species (Linton \& Wilkerson, pers. comm.). Herein all nine taxa are treated as separate species. Anopheles deaneorum, An. marajoara, and An. janconnae are proven vectors of Plasmodium in Brazil [22, 25-27]. Areas currently predicted as suitable for these species (plus An. albitarsis G, An. albitarsis $\mathrm{H}$, and $A n$. albitarsis I) largely coincide with distribution models of P. falciparum and P. vivax [24].
The Amazonian region has been identified as an especially vulnerable area for future climate changes because of the projected increase in the length of the dry season $[28,29]$, which will impact on the dynamics of infectious diseases [30]. The stability and resilience of the Amazonian climate-vegetation dynamics has been the focus of many studies aiming to understand the impacts of climate change on forest dynamics, and its potential long-term replacement by drier biomes such as the tropical savanna [31, 32], as during the mid-Pliocene [33]. Within this context, a tropical savanna biome would be more favourable for the Albitarsis Complex [24, 26]. This group is mainly associated with Plasmodium transmission as secondary vectors [24]. However, $A n$. marajoara can act as a primary vector depending on the ecological changes, especially those related to land-use and human migration [26]. Therefore, it is important to address the effects of a potential savannization of the Amazon forest on the dynamics of malaria transmission.

This study employed habitat suitability niche modelling to address potential associations among the spatial distribution of P. falciparum, An. darlingi and the nine component species of the Albitarsis Complex, considering the current environmental scenario and two scenarios of climate changes predicted for the year of 2070 . The objectives of the study were to: 1) model the potential ecological niche of P. falciparum, nine species in the Albitarsis Complex and An. darlingi; 2) estimate potential spatial distribution of nine species in the Albitarsis Complex, An. darlingi and P. falciparum in two distinct scenarios of climate changes predicted for the year of 2070; and 3) identify potential associations between the spatial distribution of $P$. falciparum and nine Albitarsis Complex species and An. darlingi.

\section{Methods}

\section{Specimen data used for analysis}

The number of occurrences of $P$. falciparum and each Anopheles species, and absence data, utilized in the species distribution modelling are shown in Table 1.

The distributions of Anopheles species and P. falciparum are shown in Fig. 1.

The geographical distribution of An. darlingi was obtained from the published literature $[27,34,35]$ and new data was obtained from field collections by ESB and MAMS (Additional file 1). Specimens of adult An. darlingi were identified by morphology using available identification keys [36].

The distribution of $P$. falciparum was obtained from The Malaria Atlas Project (MAP) [37, 38].

Species level distribution data for members of the Albitarsis Complex was achieved through molecular species verification of 1131 specimens, including topotypic and type series material, using DNA barcode sequences 
Table 1 Number of occurrences (presence data) of $P$. falciparum and each Anopheles species and absence data utilized in the species distribution modelling approach with the aid of the MaxEnt algorithm and Boosted Regression Trees

\begin{tabular}{|c|c|c|c|c|c|}
\hline & MaxEnt & & Boosted Regre & Trees & \\
\hline & Presence data & $\begin{array}{l}\text { Absence data (background points, } \\
\text { pseudo-absence) }\end{array}$ & $\begin{array}{l}\text { Presence data } \\
\text { (train data) }\end{array}$ & $\begin{array}{l}\text { Presence data } \\
\text { (test data) }\end{array}$ & $\begin{array}{l}\text { Absence data (derived from } \\
\text { MaxEnt output) }\end{array}$ \\
\hline P. falciparum & 112 & 200 & 84 & 28 & 10 \\
\hline An. darlingi & 66 & 200 & 50 & 16 & 10 \\
\hline An. albitarsis s.S. & 138 & 200 & 104 & 34 & 10 \\
\hline An. oryzalimnetes & 240 & 200 & 180 & 60 & 10 \\
\hline An. marajoara & 153 & 200 & 115 & 38 & 10 \\
\hline An. deaneorum & 70 & 200 & 53 & 17 & 10 \\
\hline An. janconnae & 96 & 200 & 72 & 24 & 10 \\
\hline An. albitarsis $F$ & 44 & 200 & 33 & 11 & 10 \\
\hline An. albitarsis $\mathrm{G}$ & 106 & 200 & 80 & 26 & 10 \\
\hline An. albitarsis $\mathrm{H}$ & 88 & 200 & 66 & 22 & 10 \\
\hline An. albitarsis I & 12 & 200 & 9 & 3 & 10 \\
\hline
\end{tabular}

(658 bp of the mitochondrial cytochrome c oxidase I gene) (see [22] for methodology). These data, generated by this team, have been previously published under the following GenBank Accession numbers: JQ614998 - JQ6 15562 [22], KJ011904 - KJ012004, KJ492398 - KJ492558 and KJ492676 - KJ492894 [24]. Detailed individual specimen level collection data are available in the Mosquito Barcoding Initiative projects on the Barcode of Life (BOLD) [39] website under the Mosquitoes of the World container project, "MBIAA: Anopheles albitarsis complex", and are available for download on VectorMap [40].

Template DNAs corresponding to GenBank Accession numbers KJ492676 - KJ492894 $(\mathrm{n}=219)$ [24] collected by MAMS and ESB are retained at $-70{ }^{\circ} \mathrm{C}$ in an entomological reference collection, the Coleção Entomológica de Referência of the Universidade de São Paulo, SP Brasil. Template DNA and other associated life stages for the remaining 912 specimens collected by RCW corresponding to GenBank Accession numbers JQ614998 - JQ615562 [22], KJ011904 - KJ012004 and KJ492398 - KJ492558 [24] are housed at the Smithsonian Institution National Museum of Natural History (NMNH), USA.

\section{Environmental variables}

Bioclimatic, topographic and biome variables were used from different data sources. The bioclimatic data were obtained from the WorldClim [41], the elevation data were from the Shuttle Radar Topography Mission (SRTM) [42] and the terrestrial biomes were from the World Wildlife Fund (WWF) [43] (see Additional file 2, Additional file 3).

\section{Species distribution modelling}

The spatial relationship between the environmental variables and presence of each Anopheles species and $P$. falciparum were carried out using the MaxEnt algorithm and Boosted Regression Trees (BRT) (see Table 1 for more information). Implementations of these methods are in the software $\mathrm{R}$ 3.0.1, in the following packages: dismo, gbm, raster, rgdal and rJava [44-48]. Further information about these methods, applied for species distribution modelling, can be found elsewhere, e.g., MaxEnt [49] and BRT [50]. For the predicted presence of $P$. falciparum, it was herein assumed that the presence of the parasite is related to environmental factors. This was considered fundamental for any climate scenario because the mosquito host is an ectotherm, and therefore the dynamics of the transmission suffers the influence of climate variables, such as temperature and precipitation (e.g., [8, 10]). Calculation of the average value between the two methods, MaxEnt and BRT, was performed in order to produce a consensus species distribution model.

\section{Environmental variables in future scenarios}

The WorldClim [51] provides bioclimatic variables from global climate models by the National Aeronautics and Space Administration (NASA) [52] and the European Network for Earth System Modelling (ENES) [53] in the fifth assessment of the Intergovernmental Panel on Climate Change, under the representative concentration pathway RCP85 (see Additional file 4, Additional file 5, and Additional file 6 for more information). The rationale for using the worst scenario among the four possible representative concentration pathways was that it would yield predictions for the most pessimistic scenario considered by the IPCC-CMIP5. The most pessimistic scenario represented a situation in which human behaviours related to climate change would stay unchanged between current and future scenarios. For the simulation 


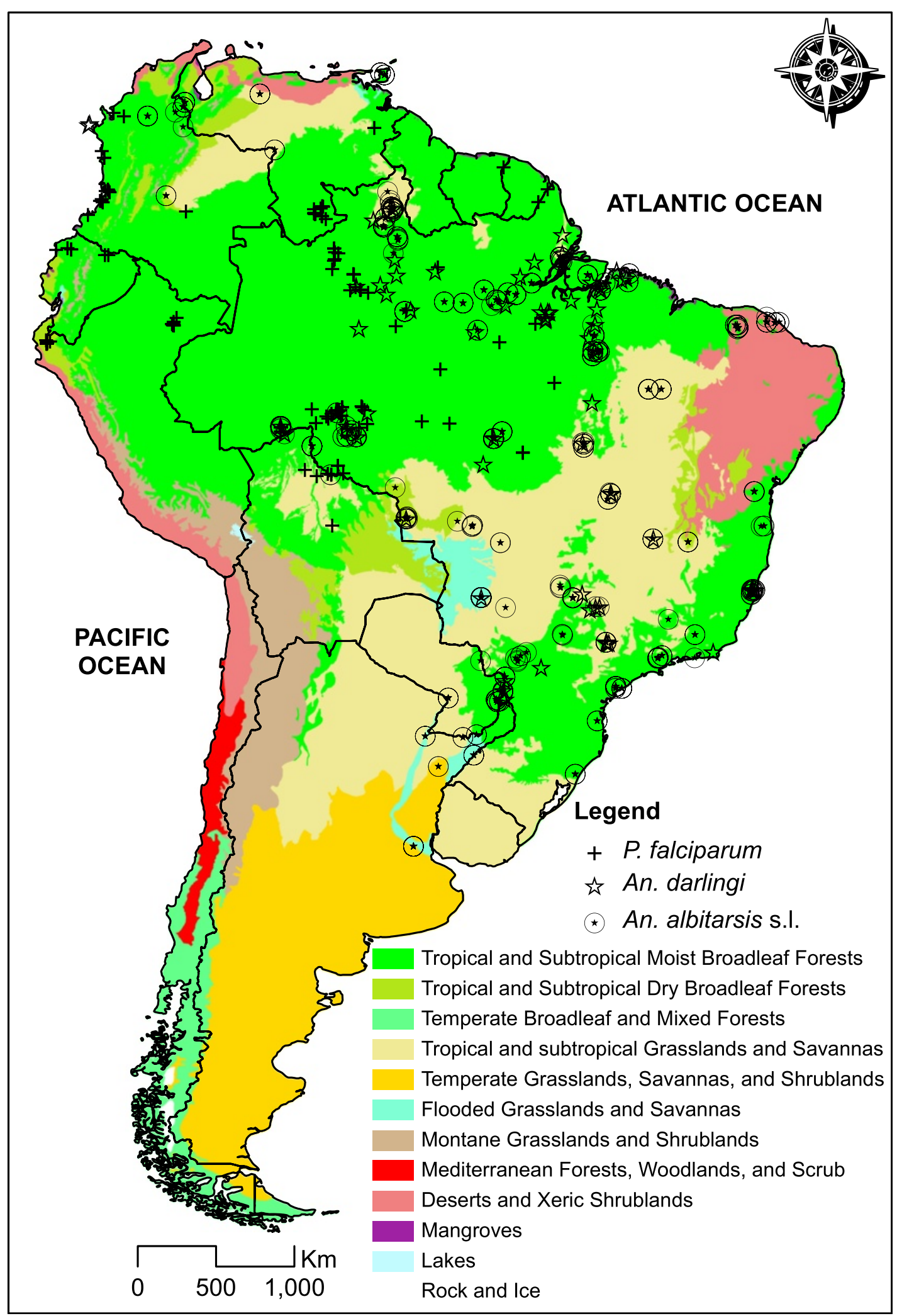

Fig. 1 Contemporary terrestrial biomes and occurrences of P. falciparum, An. darlingi and nine species in the Albitarsis Complex in South America. Sources: Biomes (the World Wildlife Fund), P. falciparum (the Malaria Atlas Project), An. darlingi (published data [27, 34, 35], plus new data obtained by ESB/MAMS [Additional file 1]) and the Albitarsis Complex (published data [22, 24]). Projection: longitude-latitude. Datum: WGS84 
tests, we assumed that in 2070 the topography of the studied region would be identical to the current topography [42]. Projection of terrestrial biome for 2070 was applied in accordance with either the contemporary situation [43] (Additional file 4, Additional file 5) or assuming modifications as in [31] (Additional file 4, Additional file 6).

\section{Projections of the species distribution model in future scenarios}

The consensus (MaxEnt $+\mathrm{BRT}$ ) species distribution model was projected onto two hypothetical scenarios: 1) Future scenario 1, based on the predictions by the NASA GISS-E2-R climate projection model [52] under CMIP5 RCP85 in 2070; 2) Future scenario 2, based on the predictions by the ENES HadGEM2-ES climate projection model [53] under CMIP5 RCP85 in 2070. In future scenario 1 , there is an increase in temperature (2-3 ${ }^{\circ} \mathrm{C}$ in average) and decrease in precipitation in the driest month/quarter $(-6.5-8 \% \mathrm{~mm})$ and in the wettest quarter $(-12 \% \mathrm{~mm})$. Biomes and topographic features are kept unaltered. Future scenario 2 is more drastic with an increase in the highest temperature $\left(4{ }^{\circ} \mathrm{C}\right.$ in average), higher annual range of precipitation (i.e., wetter $[+1-5 \% \mathrm{~mm}$ in average] wettest month/quarter and drier [-15-17 \% $\mathrm{mm}$ in average] driest month/quarter) and different biome configuration. Future scenario 1 could be considered a more conservative scenario if it was subject to less extreme events of temperature and precipitation (i.e., the coefficient of variance is smaller among predictions), while the future scenario 2 was the least optimistic as it included the possibility of extreme climate events [54], that would cause marked changes in the biome structure [31].

\section{Statistical analysis}

Cross-validation tests between species occurrence data, absence data and each species distribution model were performed to estimate a threshold at which the sum of the sensitivity (true positive) and specificity (true negative) is highest in the confusion matrix. Evaluation of MaxEnt species distribution models was performed using background points $(\mathrm{n}=200)$ as absence data (i.e., pseudoabsence). Evaluation of BRT species distribution models was done by utilizing absence data derived from MaxEnt outputs (see Table 1 for more information). The Area under the Curve (AUC) and the threshold that maximized both sensibility and specificity for each species distribution model were calculated for model evaluation.

The mean threshold for the MaxEnt and BRT species distribution models was calculated. This mean threshold value, which transformed the consensus species distribution model (probability of presence) to a binary score (presence or absence), was applied. This binary score of potential distribution of $P$. falciparum and that of each Anopheles species were associated in a 2 by 2 contingency table. An association metric (i.e., odds ratio - OR) was calculated. A result of $\mathrm{OR}<1$ showed negative association between the presence of $P$. falciparum and an Anopheles species and OR $>1$ showed a positive association between P. falciparum and an Anopheles species. A $99 \%$ confidence interval was adopted for the OR analysis.

\section{Results}

Contribution of each environmental variable for the habitat suitability models for the parasite, An. darlingi and members of the Albitarsis Complex revealed significant differential characteristics among these species, reflecting
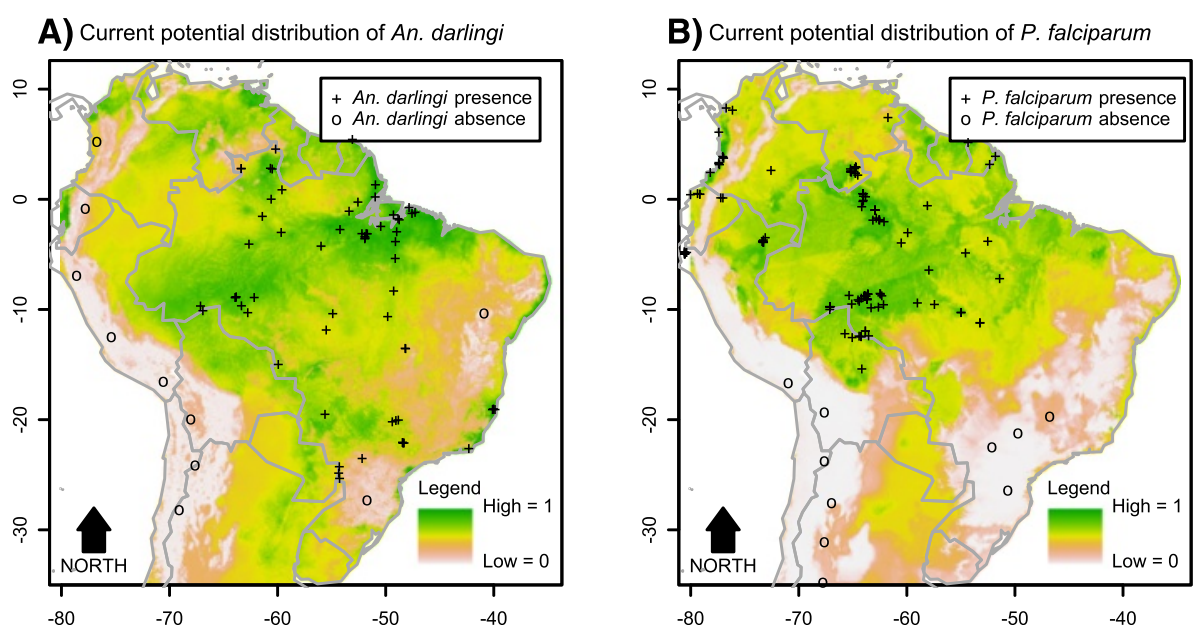

Fig. 2 Potential distribution of An. darlingi and $P$. falciparum under contemporary conditions 
specific niche requirements (Additional file 7). In the resulting maps, the estimated probabilities of potential species presence ranged from 0 (white colour) to 1 (dark green) (see gradient legend in Figs. 2, 3, 4, 5, 6, 7).

The current spatial distribution of Anopheles darlingi was positively associated with warm and humid areas (Fig. 2A) and that of P. falciparum was positively associated with higher temperatures (Fig. 2b).

The current spatial distributions of the members of the Albitarsis Complex varied significantly (Fig. 3). As can be seen from Fig. 3, Anopheles albitarsis s.s. was positively associated with cold temperatures with higher potential presence in the south of the continent. Anopheles oryzalimnetes showed a climate-generalist characteristic with potential presence in at least three distinct biomes (Amazonia, Atlantic Forest and Brazilian Savanna). Anopheles marajoara was mainly associated with the drier parts of the Amazonian biome. Anopheles deaneorum was positively associated with dry forests and savannas. Associations of An. janconnae showed that this species has restricted environmental requirements with occurrence more likely in specific hotspots of the northern part of

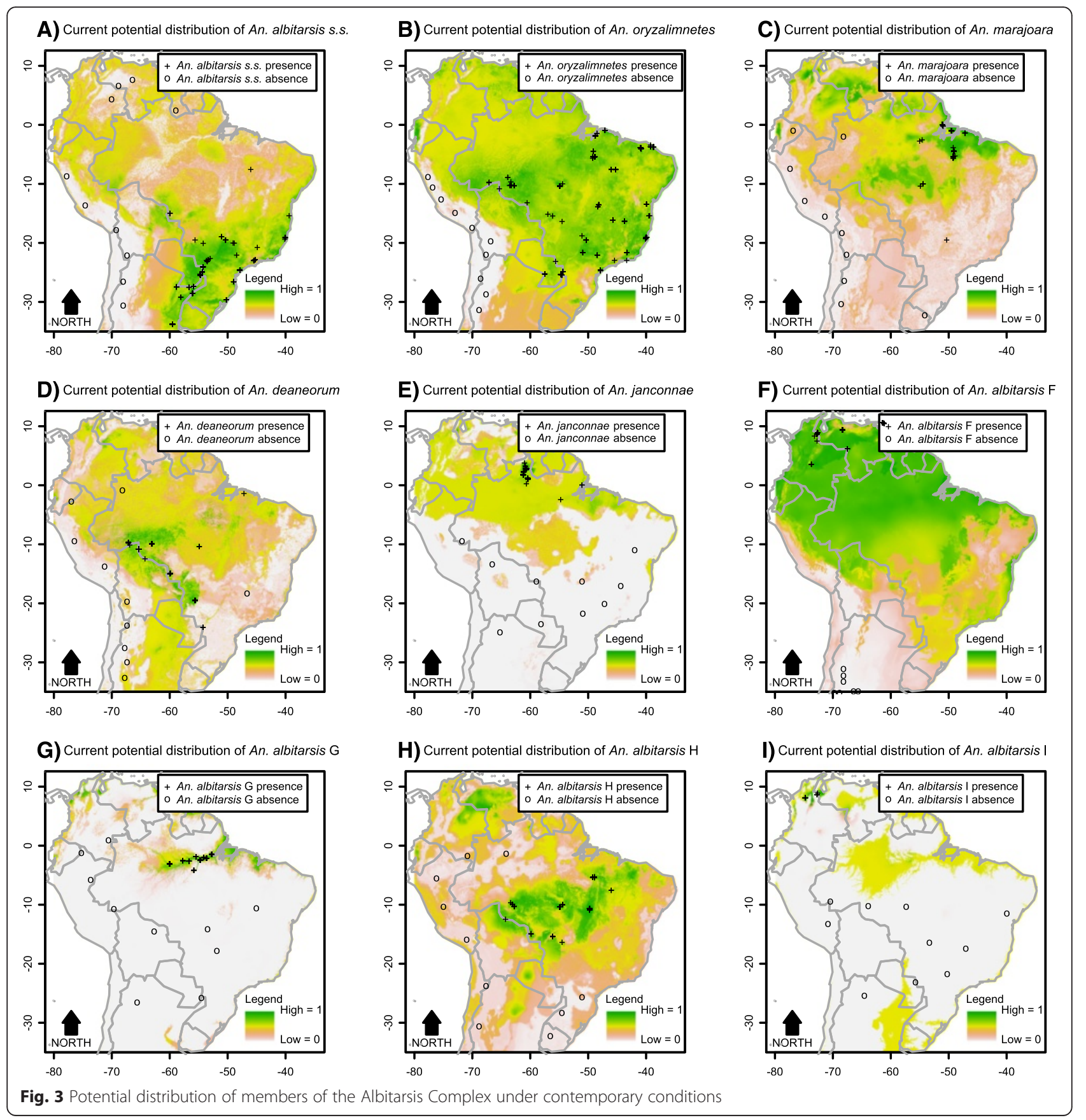



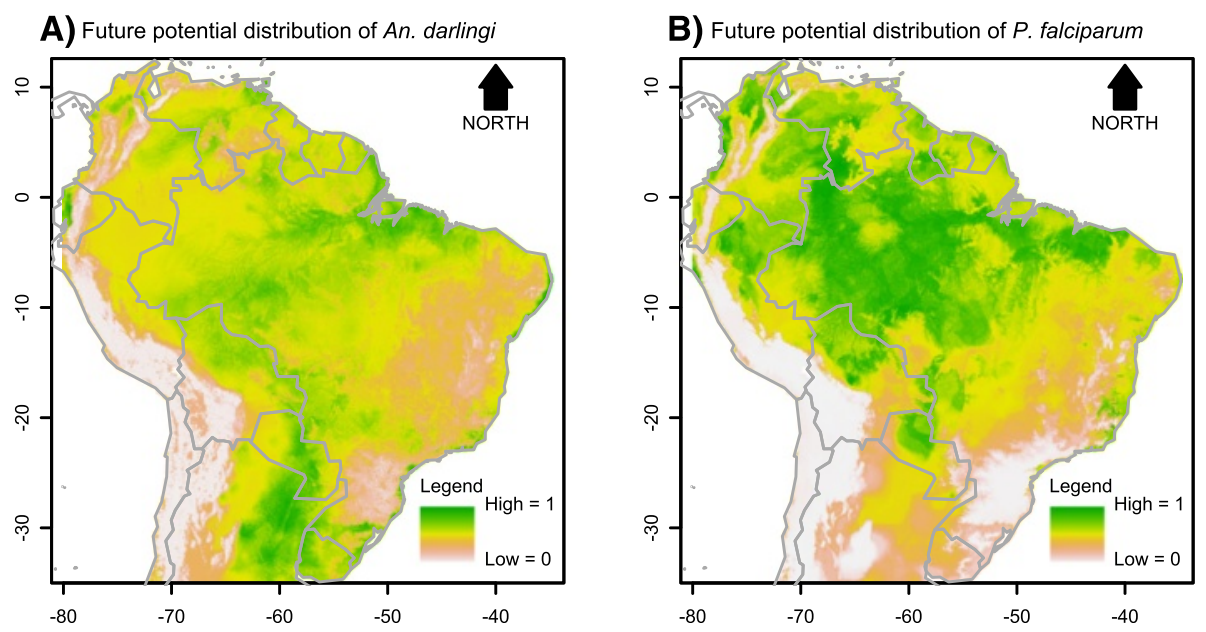

Fig. 4 Potential distribution of An. darlingi and P. falciparum under global climate change scenario 1

Amazonia. Anopheles albitarsis $\mathrm{F}$ was positively associated with the entire Amazonian biome. Anopheles albitarsis G was associated with the climatic and topographic characteristics in the Amazon River basin. Anopheles albitarsis $\mathrm{H}$ was positively associated with drier biomes such as the Brazilian Savanna. Finally, apart from the small sample size $(\mathrm{N}=12)$, it was possible to extract information from Anopheles albitarsis I current distribution which was associated with climate and topography of the northern part of the continent.

The aforementioned habitat suitability niche-based models of P. falciparum and Anopheles species were extrapolated employing two future climate scenarios: future scenario 1, conservative [climate change only] and future scenario 2, pessimistic [climate plus biome changes].

The predicted spatial distribution maps for An. darlingi for both scenarios showed that this species would decrease its presence in the Amazonian biome (Figs. 4a and 5a). This could be possible because of the decrease of precipitation in both scenarios. This further shows that An. darlingi is not a generalist species for drier environments. On the other hand, the spatial distribution of $P$. falciparum would increase in the same biome, possibly because of the increase in temperature for both scenarios, for which this species seems to be well adapted (Figs. $4 \mathrm{~b}$ and $5 \mathrm{~b}$ ).

The projected future distributions of species of the Albitarsis Complex are shown in Figs. 6 and 7. From such figures it can be seen that future spatial distribution of An. albitarsis s.s. and An. janconnae were restricted to the south and north, respectively, of the continent. This shows that both species are very sensitive to climate change. On the other hand, other species such as An. deaneorum, An. albitarsis F, An. albitarsis $\mathrm{H}$, and An. albitarsis I showed expansion on their future spatial distribution in both scenarios, whereas An. oryzalimnetes, An. marajoara, and An. albitarsis G were more likely to expand

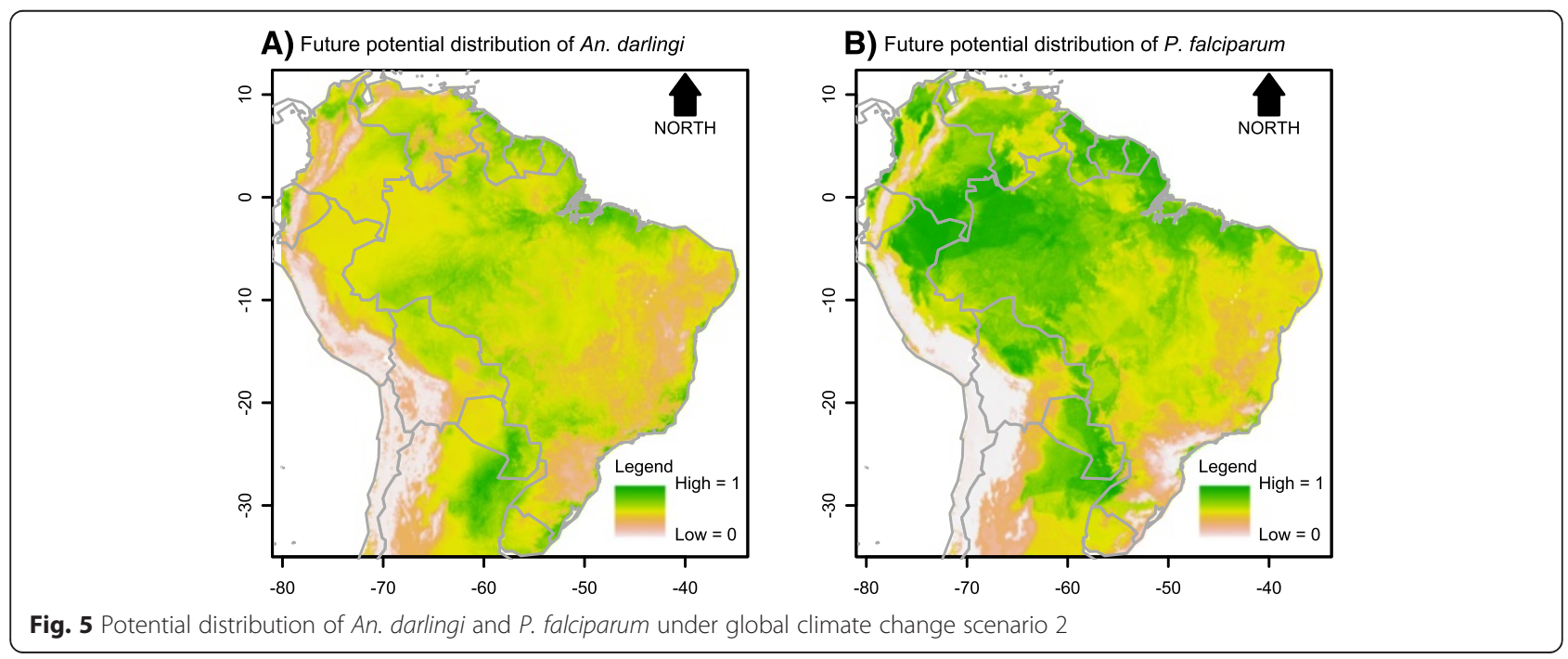




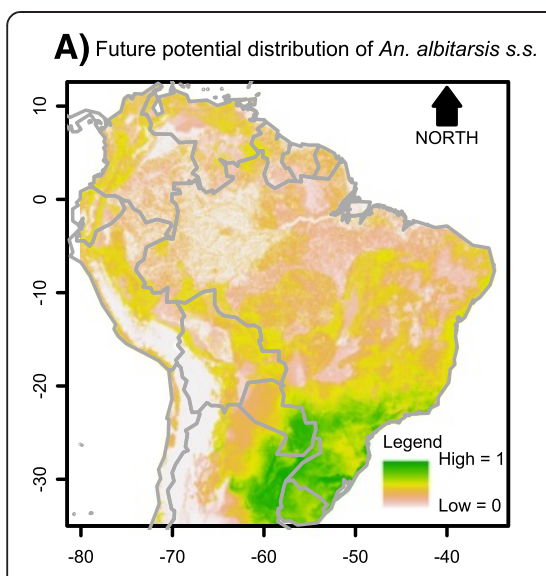

D) Future potential distribution of An. deaneorum

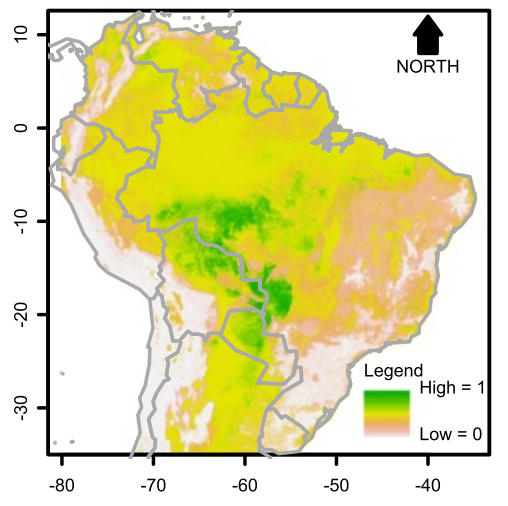

G) Future potential distribution of $A n$. albitarsis $G$

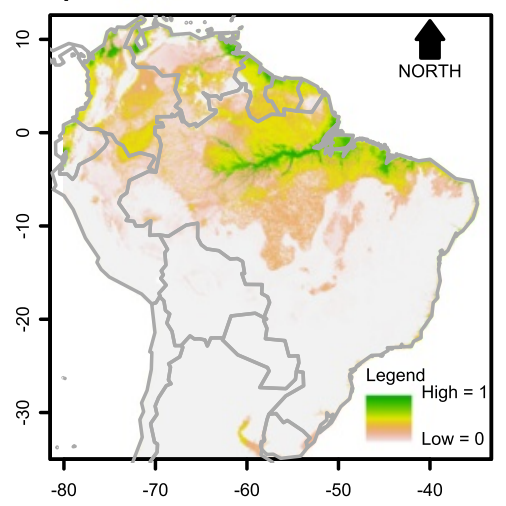

B) Future potential distribution of An. oryzalimnetes

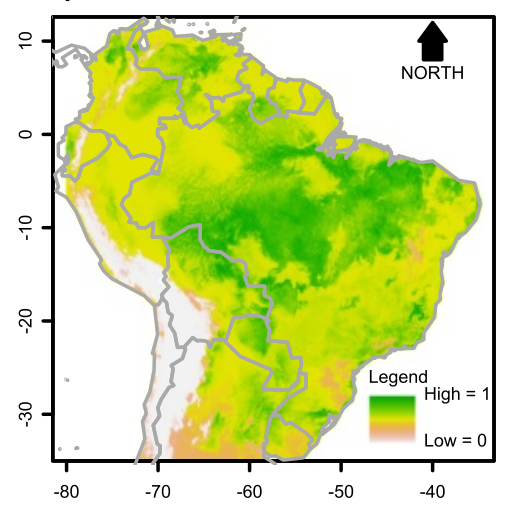

E) Future potential distribution of An. janconnae

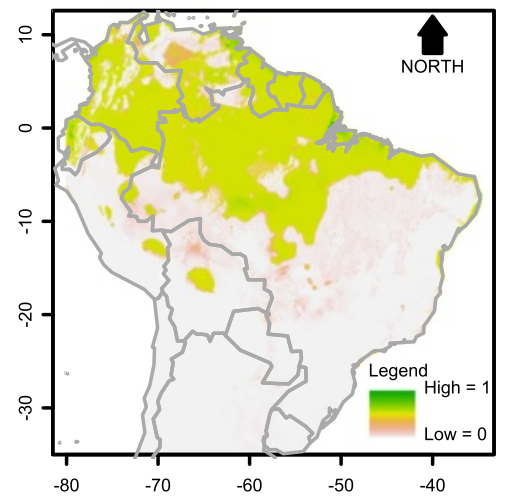

H) Future potential distribution of $A n$. albitarsis $\mathrm{H}$

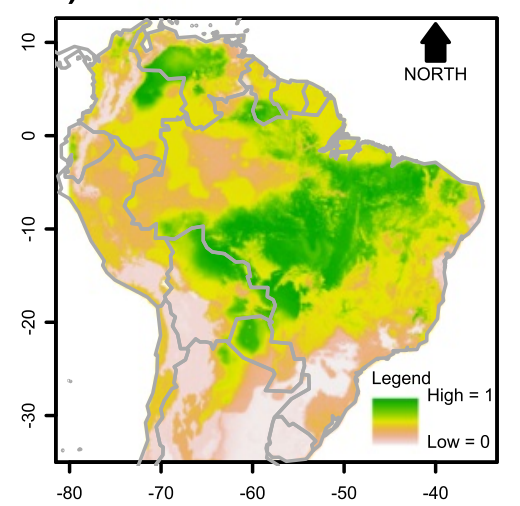

C) Future potential distribution of An. marajoara

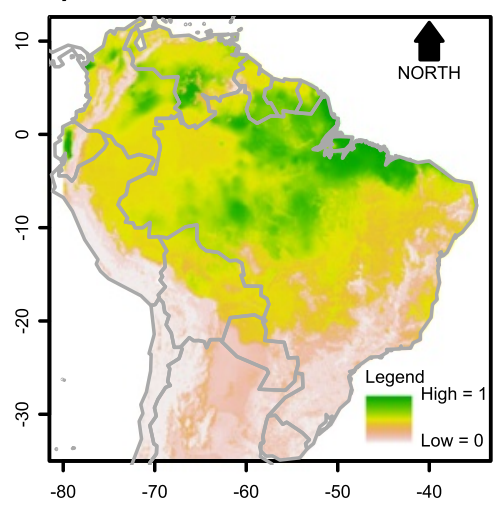

F) Future potential distribution of An. albitarsis $\mathrm{F}$

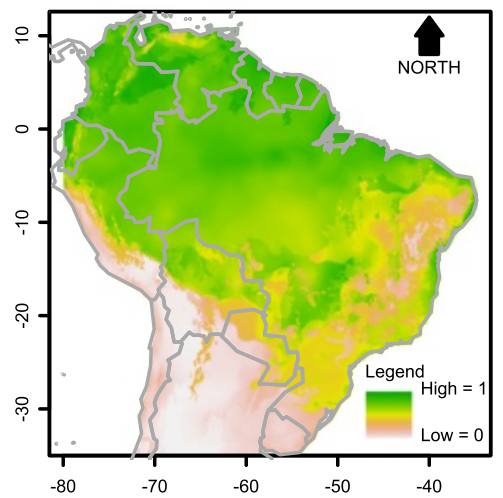

I) Future potential distribution of $A n$. albitarsis I

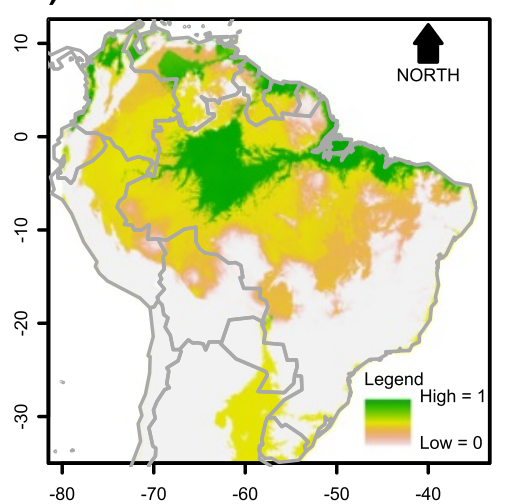

Fig. 6 Potential distribution of members of the Albitarsis Complex under global climate change scenario

their territory in future scenario 1 only. This outcome shows that some species of the Albitarsis Complex could resist climate change (An. oryzalimnetes, An. marajoara, and $A n$. albitarsis G), while others may survive under climate and biome changes (An. deaneorum, An. albitarsis $\mathrm{F}$, An. albitarsis $\mathrm{H}$, and An. albitarsis I).

There were shifts in the predicted presence of $A n$. darlingi, P. falciparum and An. deaneorum from current to future scenarios (Fig. 8). The current spatial distribution of $P$. falciparum was positively associated with higher temperatures. In future scenarios 1 and 2 , in which temperature was higher, this parasite species expanded its distribution in South America. In the current scenario, coverage of $P$. falciparum in South America was $25 \%$, increasing to $35 \%$ in future scenario 1 and $46 \%$ in future scenario 2 (Fig. 8). Higher levels of precipitation positively influenced current spatial distribution of An. darlingi. In future scenarios 1 and 2, where precipitation decreases, its distribution in South America also decreases. The current coverage of An. darlingi decreased 


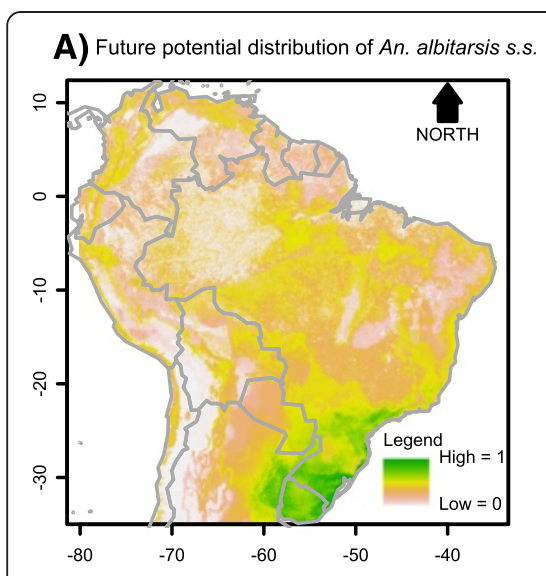

D) Future potential distribution of $A n$. deaneorum

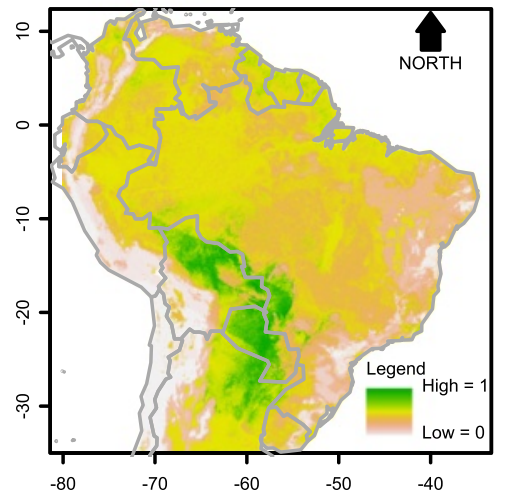

G) Future potential distribution of $A n$. albitarsis $\mathrm{G}$

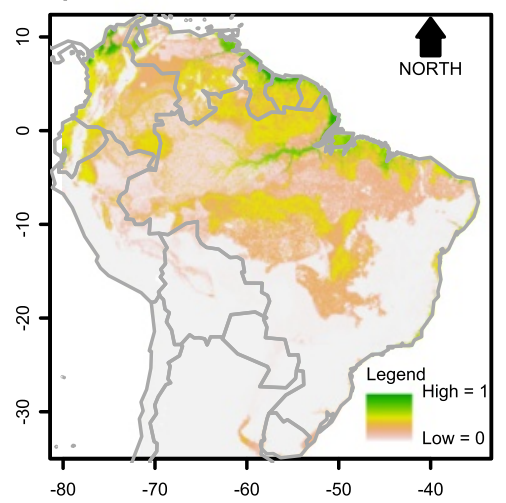

B) Future potential distribution of An. oryzalimnetes

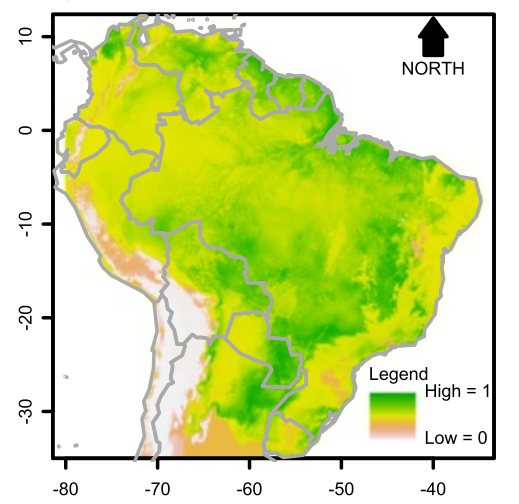

E) Future potential distribution of An. janconnae

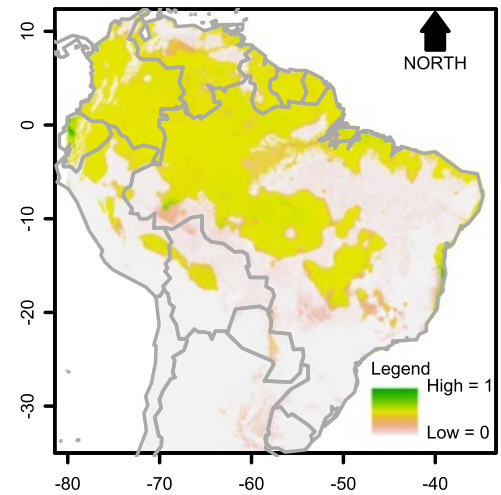

H) Future potential distribution of An. albitarsis $\mathrm{H}$

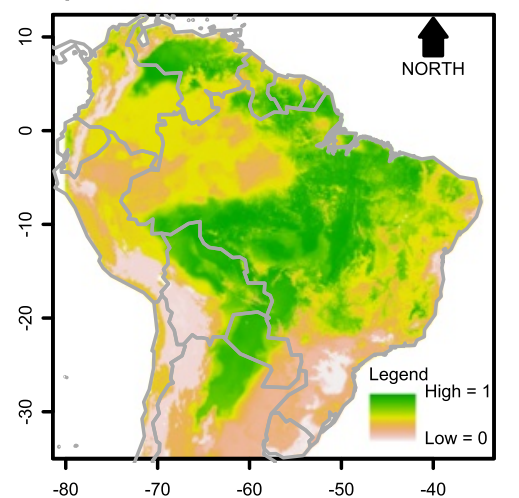

C) Future potential distribution of An. marajoara

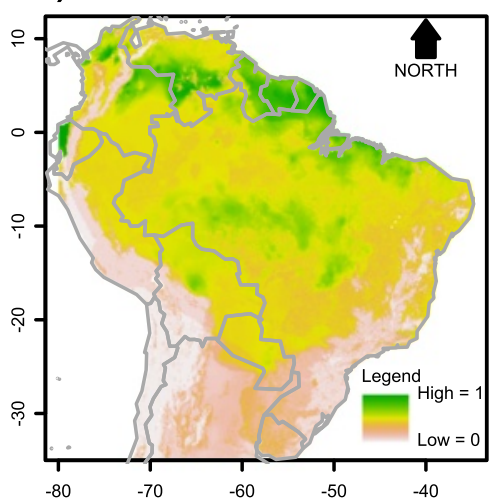

F) Future potential distribution of $A n$. albitarsis $\mathrm{F}$

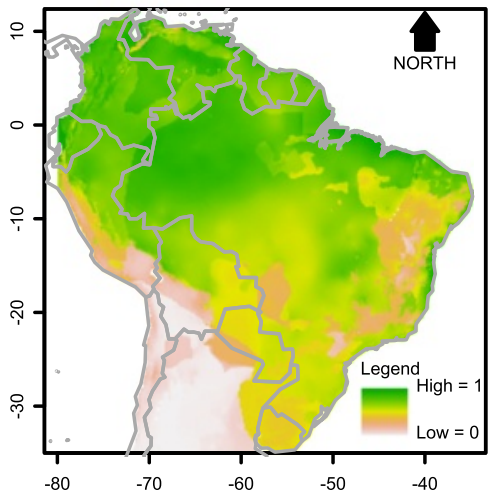

I) Future potential distribution of An. albitarsis I

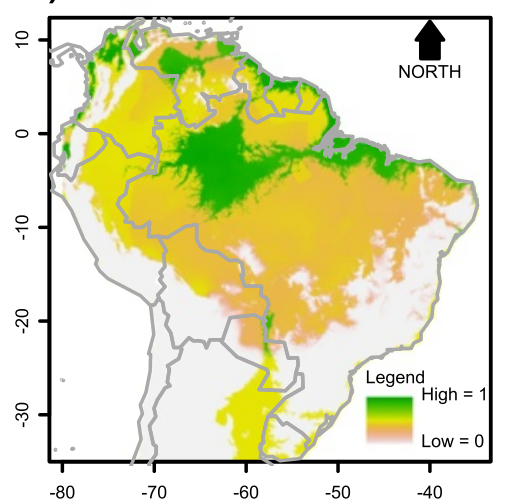

Fig. 7 Potential distribution of members of the Albitarsis Complex under global climate change scenario 2

from $21 \%$ to $11 \%$ in scenario 1 and $8 \%$ in scenario 2 (Fig. 8). In those Albitarsis Complex species for which precipitation was an important predictor (e.g., An. albitarsis s.s.), all showed decreased distributions in both future scenarios. On the contrary, other species benefitted from either temperature increase or altered biome configuration resulting in the expansion of their spatial distributions in future scenarios. For example, coverage of $A n$. deaneorum increased from its current value of $6 \%$ to $8 \%$ in scenario 1 and $9 \%$ in scenario 2 (Fig. 8).
Spatial associations of binary (presence/absence) species distribution models between $P$. falciparum and each Anopheles in all scenarios are in Table 2. Spatial association between the parasite and An. darlingi decreased in future scenarios. On the contrary, spatial associations between $P$. falciparum and species of the Albitarsis Complex, particularly An. oryzalimnetes, An. marajoara, An. deaneorum, An. albitarsis G, An. albitarsis $\mathrm{H}$, and $A n$. albitarsis I, increased in both future scenarios. 


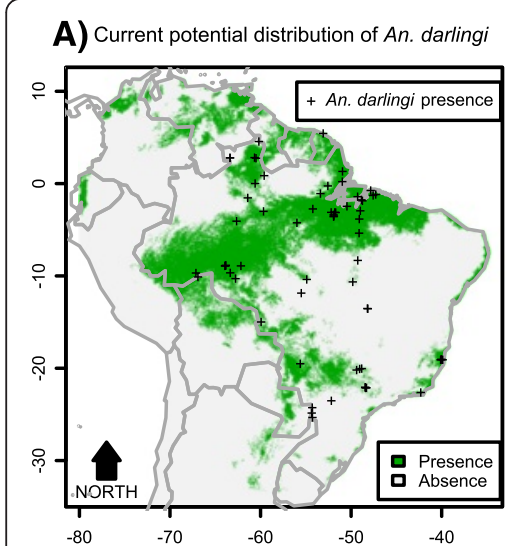

D) Future potential distribution of An. darlingi

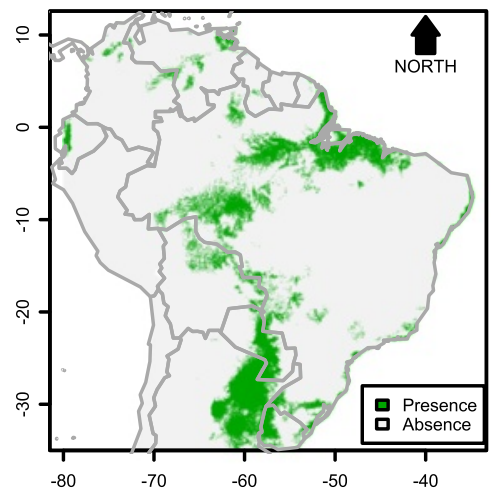

G) Future potential distribution of An. darlingi

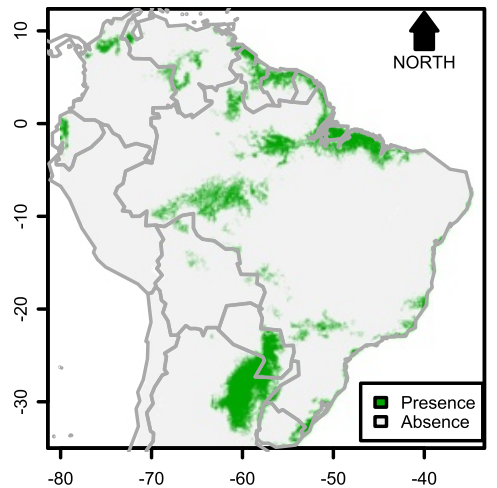

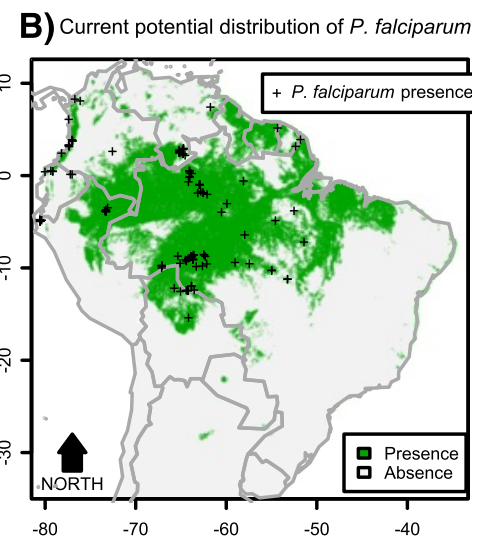

B) Future potential distribution of $P$. falciparum

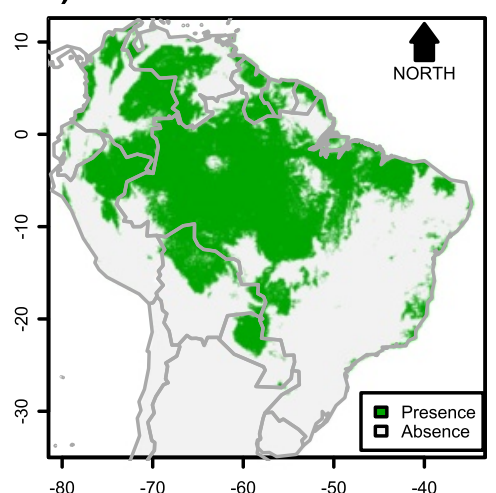

H) Future potential distribution of $P$. falciparum

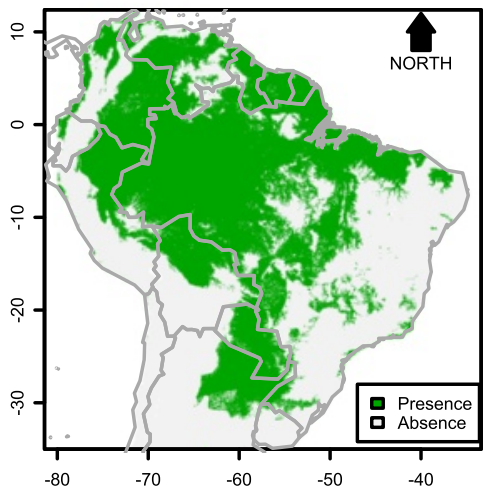

C) Current potential distribution of An. deaneorum

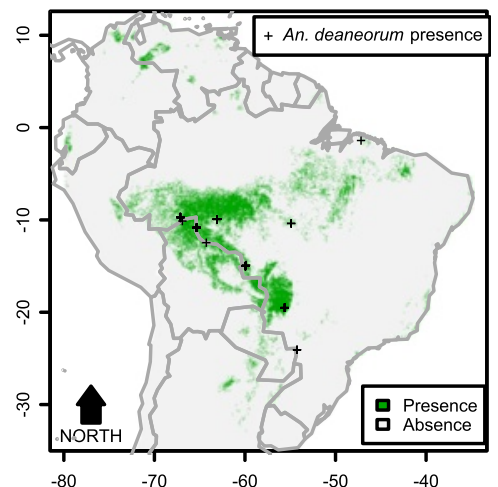

F) Future potential distribution of An. deaneorum

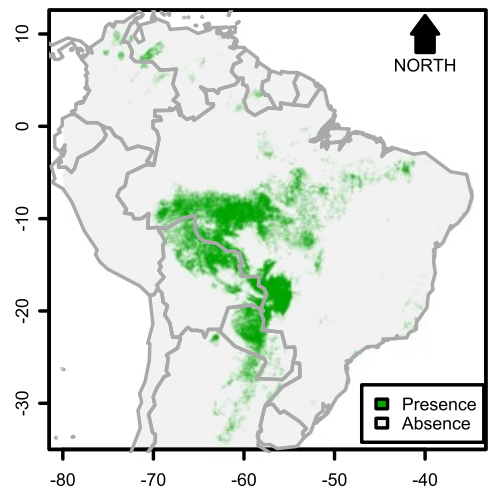

I) Future potential distribution of An. deaneorum

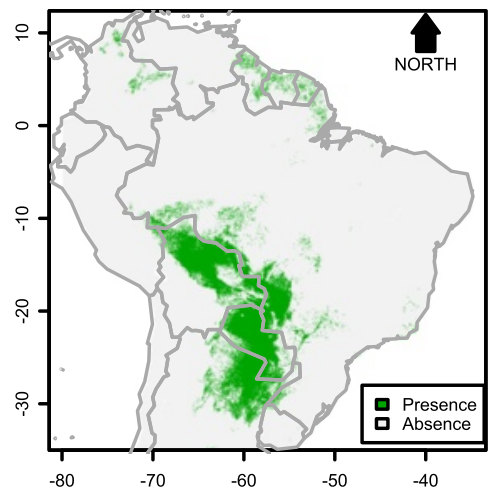

Fig. 8 Potential distribution of An. darlingi and P. falciparum and An. deaneorum under contemporary conditions, global climate change scenario 1 , and global climate change scenario 2

\section{Discussion}

Probable spatial distributions of the malarial parasite $P$. falciparum and ten Neotropical Anopheles species were predicted using an ecological niche modelling approach that included climate factors, topographical and biomic variables under the current malaria transmission setting in South America. In a second round of analyses, the currently predicted niche model for each species was addressed employing two potential scenarios of future climate and biome changes in 2070, with the assumption that climate change would progress under a high emission scenario (i.e., RCP8.5). A significant potential shift in the respective roles of the current major mosquito vector species of $P$. falciparum was indicated using two distinct scenarios of climate and environmental changes predicted for 2070. Our analyses showed that whereas the role of the major current vector $A n$. darlingi in malaria transmission may decrease in future, some species of the Albitarsis Complex (An. marajoara, An. deaneorum, An. albitarsis G, An. albitarsis H, and An. albitarsis I) may 
Table 2 Spatial association of species distribution models of $P$. falciparum against each Anopheles vector according to present and future scenarios, South America

\begin{tabular}{llll}
\hline & $\begin{array}{l}\text { Current } \\
\text { P. falciparum } \\
\text { OR (Cl99\%) }\end{array}$ & $\begin{array}{l}\text { Future (scenario1) } \\
\text { P. falciparum } \\
\text { OR (Cl99\%) }\end{array}$ & $\begin{array}{c}\text { Future (scenario2) } \\
\text { P. falciparum } \\
\text { OR (Cl99\%) }\end{array}$ \\
\hline An. darlingi & $7.42(7.39,7.44)$ & $2.48(2.48,2.49)$ & $6.51(6.47,6.54)$ \\
An. marajoara & $8.02(7.97,8.06)$ & $9.71(9.67,9.77)$ & $11.3(11.21,11.41)$ \\
An. deaneorum & $6.21(6.18,6.24)$ & $11.66(11.59,11.72)$ & $10.25(10.19,10.31)$ \\
An. janconnae & $3.41(3.38,3.45)$ & $2.18(2.14,2.22)$ & $0.89(0.87,0.91)$ \\
An. albitarsis s.s. & $0.08(0.08,0.08)$ & $0.03(0.03,0.03)$ & $0.33(0.33,0.33)$ \\
An. oryzalimnetes & $1.91(1.9,1.91)$ & $9.21(9.18,9.24)$ & $3.13(3.12,3.14)$ \\
An. albitarsis F & $10.29(10.26,10.33)$ & $5.41(5.39,5.42)$ & $6.92(6.9,6.94)$ \\
An. albitarsis G & $4.72(4.66,4.77)$ & $7.55(7.46,7.64)$ & $28.83(27.78,29.89)$ \\
An. albitarsis H & $3.48(3.47,3.49)$ & $9.36(9.33,9.39)$ & $6.57(6.55,6.58)$ \\
An. albitarsis I & $1.2(1.16,1.23)$ & $21.6(21.48,21.73)$ & $44.89(44.38,45.34)$ \\
\hline
\end{tabular}

adopt a more significant role as either primary or secondary vectors of $P$. falciparum in South America. Because of a potential distribution expansion in some species of the Albitarsis Complex, the geographical distribution of the parasite could exacerbate, from few-clustered parasite populations at present to a hugely increased potential 35-46\% coverage of South America by 2070. This result is consistent with the results found by Caminade et al. [11], in which they showed that $P$. falciparum would expand its current distribution towards areas situated in greater latitudes and altitudes, if the temperatures in those areas increased. Additional supporting evidences were found in highland ecosystems in where parasites and vectors had expanded their geographic distributions towards malaria-free highlands because of climatic and socio-economic changes $[55,56]$.

The distribution of $A n$. darlingi, which is dependent on high precipitation levels [57], decrease markedly in both future scenarios of climate changes tested in the present study. This result is consistent with the arguments of Parham and Michael [10] regarding the association of climate variables, such as levels of precipitation and temperature, and their role as potential driving forces to the rate of malaria transmission. This further relates to the evidences that an optimum threshold of malaria emergence could occur under combining effects of temperature and precipitation $[58,59]$. In contrast, spatial distributions of the component species of the Albitarsis Complex seem to be less dependent on precipitation levels [24]. The evidence that effects of climate change on vector abundance require species-specific combinations further supports this result [60]. Therefore, in future scenarios subject to climate changes, dynamics of malaria could have such species, particularly $A n$. marajoara and $A n$. deaneorum, as local primary vectors of $P$. falciparum in forest areas that can follow a savannization process.
The core message in the present work is that future scenarios may lead to shifts in the relative importance of species of the Albitarsis Complex over An. darlingi for transmission of $P$. falciparum in South America. It is not possible, however, at this stage, to confirm that future distribution of malaria will decrease or not because the human control efforts were not included as predictors in the projected scenarios. Additionally, further implementations on the projected scenarios would be to consider the effects of future climate change on the quality of larval habitat, as this potentially is an important predictor to malaria transmission [61]. On the other hand, Foley et al. [24], who utilized the same dataset of specimens of the Albitarsis Complex used herein, but in a different approach, showed that vector species shifts are likely to occur in South America. More specifically, these authors showed that long term changes in precipitation could affect vector abundance and distribution differently, possibly increasing the chances of $A n$. marajoara compared to species more sensitive to water unavailability, such as $A n$. albitarsis s.s., or An. darlingi, according to the present study. Vector species shifts may further relate to the magnitude of vector richness in a certain region because the pool of competent vectors in a mosquito assemblage could likely be an important predictor to malaria resilience, as supported recently [62].

The link between future scenarios under climate change effects and Amazonian savannization process has long been recognized [31, 32]. During a savannization process, Amazonian tropical evergreen forests would be replaced by drier and less productive biomes such as savanna, shrub land or even semi-desert [31]. Amazonian forest could be subject to a decreased precipitation, and a few models suggest the extensive possibility of retreat of the forest [32]. Potential interactions between climate changes and land-use changes may strongly influence 
the Amazonian ecosystem in the future [28]. Changes in land-use and human migration patterns have already affected malaria transmission in areas of the municipality of Macapá, in Amapá state in the Amazon forest [26], with the replacement of the primary vector $A n$. darlingi by a secondary vector An. marajoara [26]. The ecological niches of members of the Albitarsis Complex are dependent upon long-term changes in precipitation and, especially, the increased duration of the dry season can increase the abundance and distribution of some species of this group [24]. This may be indicative that these species will succeed at colonizing savanna forest in future scenarios.

\section{Conclusions}

Climatic and landscape effects caused by global warming will facilitate expanded distributions and, consequentially, increasingly important roles for component species in the Albitarsis Complex as important malaria vectors. This further highlights the need for further detailed studies elucidating the respective bionomics, ecology and epidemiological roles of component members of the Albitarsis Complex.

\section{Additional files}

\section{Additional file 1: Tabular data in Excel Spreadsheet. Anopheles darlingi Occurrence Data. (XLSX 12 kb) \\ Additional file 2: Figure S9. Environmental predictors (bioclimatic data, elevation and terrestrial biomes) under contemporary conditions. Sources: Hijmans et al. [41], the Shuttle Radar Topography Mission [42] and the World Wildlife Fund [43]. (PDF $292 \mathrm{~kb}$ )}

Additional file 3: Table S3. Description of environmental variables utilized in the niche modelling of P. falciparum and Anopheles vectors in South America, at present. (DOCX $14 \mathrm{~kb}$ )

Additional file 4: Table S4. Description of environmental variables utilized in simulations of future scenarios of the niche model of $P$. falciparum and Anopheles vectors in South America, 2070. (DOCX $15 \mathrm{~kb}$ )

Additional file 5: Figure S10. Environmental variables (bioclimatic data, topographic and terrestrial biomes) under global climate change scenario 1. Sources: the NASA Goddard Institute for Space Studies [52], the Shuttle Radar Topography Mission [42] and the World Wildlife Fund [43]. (PDF $293 \mathrm{~kb}$ )

Additional file 6: Figure S11. Environmental variables (bioclimatic data topographic and terrestrial biomes) under global climate change scenario 2. Sources: the ENES Met Office Hadley Centre [53], the Shuttle Radar Topography Mission [42] and Lapola et al. [31]. (PDF 321 kb)

Additional file 7: Table S5. Relative contribution (\%) of environmental variables to predicted values in the MaxEnt algorithm and Boosted Regression Trees (BRT) for each species in South America. (DOCX $16 \mathrm{~kb}$ )

\section{Competing interests}

The authors declare that they have no competing interests.

\section{Authors' contributions}

GZL and MAMS conceived the idea. GZL, YML, RCW, MAMS participated in the study design. RCW, ESB, SSN, DCS, MAMS executed the fieldwork. GZL, YML, RCW, MAMS analysed and interpreted the data. GZL, YML, RCW, MAMS wrote the manuscript. All authors read and approved the final version.

\section{Acknowledgements}

We gratefully acknowledge financial support from the São Paulo Research Foundation (FAPESP, Grant no. 2014/26229-7), the Brazilian National Council for Scientific and Technological Development (CNPq, Grant no. 301666/20113) to MAMS; RCW was partially supported by an award from the National Institute of Health, USA (grant R01 Al50139-02 to Jan Conn). GZL is currently financially supported by FAPESP Grant no. 2014/09774-1 and FAPESP Grant no. 2015/09669-6. Funders of this study had no role in the design, collection, analysis or interpretation of the results, nor in the writing of this report or the decision to publish it. Part of this research was performed under a Memorandum of Understanding between the Walter Reed Army Institute of Research and the Smithsonian Institution, with institutional support provided by both organizations. The material to be published reflects the views of the authors and should not be construed to represent those of the US Department of the Army or the US Department of Defense. This manuscript was prepared whilst YML held a National Research Council (NRC) Senior Research Associateship Award at the Walter Reed Army Institute of Research.

\section{Author details}

'Departamento de Epidemiologia, Faculdade de Saúde Pública, Universidade de São Paulo, São Paulo, SP, Brazil. 'Laboratório de Informática Médica, Faculdade de Medicina, Universidade de São Paulo, São Paulo, SP, Brazil. ${ }^{3}$ Setor de Pós-graduação, Pesquisa e Inovação, Faculdade de Medicina do ABC, Santo André, SP, Brazil. ${ }^{4}$ Division of Entomology, Walter Reed Army Institute of Research, Silver Spring, MD, USA. ${ }^{5}$ Walter Reed Biosystematics Unit, Museum Support Center, Smithsonian Institution, Suitland, MD, USA. ${ }^{6}$ Department of Entomology, National Museum of Natural History, Smithsonian Institution, Washington, DC, USA. ${ }^{7}$ Department of Preventative Medicine and Biostatistics, Uniformed Services University of the Health Sciences, Bethesda, MD, USA. ${ }^{8}$ Superintendência de Controle de Endemias (SUCEN), Secretaria de Estado da Saúde de São Paulo, Araraquara, SP, Brazil.

Received: 9 January 2015 Accepted: 6 August 2015

Published online: 19 August 2015

\section{References}

1. Anderegg WRL, Prall JW, Harold J, Schneider SH. Expert credibility in climate change. Proc Natl Acad Sci USA. 2010;107:12107-9.

2. Cook J, Nuccitelli D, Green SA, Richardson M, Winkler B, Painting R, et al. Quantifying the consensus on anthropogenic global warming in the scientific literature. Environ Res Lett. 2013;8:024024.

3. Maibach E, Myers T, Leiserowitz A. Climate scientists need to set the record straight: There is a scientific consensus that human-caused climate change is happening. Earth's Future. 2014;2:295-8.

4. American Association for the Advancement of Science (AAAS). In: Statement on climate change from 18 scientific associations. 2009. http:// www.aaas.org/sites/default/files/migrate/uploads/1021climate_letter1.pdf. Accessed on 03 July 2015.

5. Intergovernmental Panel for Climate Change (IPCC). Welcome statement by Rajendra K. Pachauri, Chair of the IPCC. 2014. http://www.ipcc.ch/pdf/ar5/ Dr.\%20Pachauri\%200pening\%20Statement.pdf. Accessed on 03 July 2015.

6. Patz JA, Frumkin $\mathrm{H}$, Holloway $\mathrm{T}$, Vimont DJ, Haines A. Challenges and opportunities for global health. JAMA. 2014; doi:10.1001/jama.2014.13186

7. Githeko AK, Lindsay SW, Confalonieri UE, Patz JA. Climate change and vector-borne diseases: a regional analysis. Bull World Health Org. 2000;78:1136-47.

8. Mordecai EA, Paaijmans KP, Johnson LR, Balzer C, Ben-Horin T, de Moor E, et al. Optimal temperature for malaria transmission is dramatically lower than previously predicted. Ecol Lett. 2013;16:22-30.

9. Lunde TM, Bayoh MN, Lindtjorn B. How malaria models relate temperature to malaria transmission. Parasit Vectors. 2013;6:20.

10. Parham PE, Michael E. Modeling the effects of weather and climate change on malaria transmission. Environ Health Perspect. 2010;1 18:620-6.

11. Caminade C, Kovats S, Rocklov J, Tompkins AM, Morse AP, Colón-González FJ, et al. Impact of climate change on global malaria distribution. Proc Natl Acad Sci USA. 2014;111:3286-91.

12. Drake JM, Beier JC. Ecological niche and potential distribution of Anopheles arabiensis in Africa in 2050. Malaria J. 2014;13:213.

13. Barreto ML, Teixeira MG, Bastos FI, Ximenes RAA, Barata RB, Rodrigues $L C$. Successes and failures in the control of infectious diseases in Brazil: social 
and environmental context, policies, interventions, and research needs. The Lancet. 2011;377:1877-89.

14. Brazilian Ministry of Health (BRZ-MS). Sistema de Vigilância Epidemiológica de Notificação de Casos de Malária - SIVEP-MALARIA. 2013. http:// portalweb04.saude.gov.br/sivep_malaria/default.asp. Accessed on 15 July 2015.

15. Batista EPA, Costa EFM, Silva AA. Anopheles darlingi (Diptera: Culicidae) displays increased attractiveness to infected individuals with Plasmodium vivax gametocytes. Parasit Vectors. 2014;7:251.

16. Molino-Cruz A, Barillas-Mury C. The remarkable journey of adaptation of the Plasmodium falciparum malaria parasite to New World anopheline mosquitoes. Mem Inst Oswaldo Cruz. 2014;109:1-6.

17. Rios-Velásquez CM, Martins-Campos KM, Simões RC, Izzo T, dos Santos EV, et al. Experimental Plasmodium vivax infection of key Anopheles species from the Brazilian Amazon. Malaria J. 2013;12:460.

18. Wilkerson RC, Parsons TJ, Klein TA, Gaffigan TV, Bergo E, Consolim J. Diagnosis by random amplified polymorphic DNA polymerase chain reaction of four cryptic species related to Anopheles (Nyssorhynchus) albitarsis (Diptera: Culicidae) from Paraguay, Argentina, and Brazil. J Med Entomol. 1995:32:697-704.

19. Lehr MA, Kilpatrick CW, Wilkerson RC, Conn JE. Cryptic species in the Anopheles (Nyssorhynchus) albitarsis (Diptera: Culicidae) complex: incongruence between random amplified polymorphic DNA-polymerase chain reaction identification and analysis of mitochondrial DNA COI gene sequences. Ann Entomol Soc Am. 2005;98:908-17.

20. Brochero $\mathrm{HH}$, Li C, Wilkerson RC. A newly recognized species in the Anopheles (Nyssorhynchus) albitarsis complex (Diptera: Culicidae) from Puerto Carreno, Colombia. Am J Trop Med Hyg. 2007;76:1113-7.

21. Gutiérrez LA, Orrego LM, Gómez GF, López A, Luckhart S, Conn JE, et al. A new mtDNA COI gene lineage closely related to Anopheles janconnae of the Albitarsis complex in the Caribbean region of Colombia. Mem Inst Oswaldo Cruz. 2010;105:1019-25.

22. Ruiz-Lopez F, Wilkerson RC, Conn JE, McKeon SN, Levin DM, Quiñones ML, et al. DNA barcoding reveals both known and novel taxa in the Albitarsis Group (Anopheles: Nyssorhynchus) of Neotropical malaria vectors. Parasit Vectors. 2012;5:44.

23. Motoki MT, Wilkerson RC, Sallum MA. The Anopheles albitarsis complex with the recognition of Anopheles oryzalimnetes Wilkerson and Motoki, n. sp. and Anopheles janconnae Wilkerson and Sallum, n. sp. (Diptera: Culicidae). Mem Inst Oswaldo Cruz. 2009;104:823-50.

24. Foley D, Linton YM, Ruiz-Lopez F, Conn JE, Sallum MAM, Póvoa MM, et al. Geographic distribution, evolution, and disease importance of species within the Neotropical Anopheles albitarsis Group (Diptera, Culicidae). J Vect Ecol. 2014:39:168-81.

25. Klein TA, Lima JB, Tada MS. Comparative susceptibility of anopheline mosquitoes to Plasmodium falciparum in Rondônia, Brazil. Am J Trop Med Hyg. 1991;44:598-603.

26. Conn JE, Wilkerson RC, Segura NO, Souza RTL, Schlichting CD, Wirtz RA, et al. Emergence of a new Neotropical malaria vector facilitated by human migration and changes in land use. Am J Trop Med Hyg. 2002;66:18-22.

27. Póvoa MM, de Souza RTL, Lacerda RNL, Rosa ES, Galiza D, de Souza JR, et al. The importance of Anopheles albitarsis $\mathrm{E}$ and An. darlingi in human malaria transmission in Boa Vista, state of Roraima, Brazil. Mem Inst Oswaldo Cruz. 2006:101:163-8.

28. Brando PM, Balch JK, Nepstad DC, Morton DC, Putz FE, Coe MT, et al. Abrupt increases in Amazonian tree mortality due to drought-fire interactions. Proc Natl Acad Sci USA. 2014;111:6347-52.

29. Fu R, Yin L, Li W, Arias PA, Dickinson RE, Huang L, et al. Increased dryseason length over southern Amazonia in recent decades and its implication for future climate projection. Proc Natl Acad Sci USA. 2013;110:18110-5.

30. Confalonieri UE, Margonari C, Quintão AF. Environmental change and the dynamics of parasitic diseases in the Amazon. Acta Trop. 2014;129:33-41.

31. Lapola DM, Oyama MD, Nobre CA. Exploring the range of climate biome projections for tropical South America: the role of $\mathrm{CO}_{2}$ fertilization and seasonality. Glob Biogeochem Cycles. 2009;23, GB3003.

32. Zelazowski P, Malhi Y. Huntingford, Sitch S, Fisher JB. Changes in the potential distribution of humid tropical forests on a warmer planet. Phil Trans R Soc A. 2011;369:137-60.

33. Willis KJ, MacDonald GM. Long-term ecological records and their relevance to climate change predictions for a warmer world. Ann Rev Ecol Evol Syst. 2011;42:267-87.
34. Mirabello L, Conn JE. Molecular population genetics of the malaria vector Anopheles darlingi in Central and South America. Heredity. 2006;96:311-21.

35. Emerson KJ, Conn JE, Bergo ES, Randel MA, Sallum MAM. Brazilian Anopheles darling Root (Diptera: Culicidae) clusters by major biogeographical region. PLoS One. 2015;10, e0130773.

36. Forattini OP. Culicidologia Médica. São Paulo, SP, Brazil: EDUSP; 2002

37. Gething PW, Patil AP, Smith DL, Guerra CA, Elyazar IRF, Johnston GL, et al. A new world malaria map: Plasmodium falciparum endemicity in 2010. Malaria J. $2011 ; 10: 378$

38. The Malaria Atlas Project. 2015. http://www.map.ox.ac.uk/. Accessed in 03 July 2015.

39. Barcode of Life. 2015. http://www.boldsystems.org/. Accessed in 24 July 2015

40. VectorMap. 2015. http://www.vectormap.org/. Accessed in 24 July 2015.

41. Hijmans RJ, Cameron SE, Parra JL, Jones PG, Jarvis A. Very high resolution interpolated climate surfaces for global land areas. Int J Climatol. 2005;25:1965-78.

42. The Shuttle Radar Topography Mission. 2015. http://srtm.usgs.gov/. Accessed on 03 July 2015.

43. The World Wildlife Fund. 2015. http://www.worldwildlife.org/. Accessed on 03 July 2015.

44. Hijmans RJ, Phillips S, Leathwick J, Elith J. dismo: Species distribution modeling. R package version 0.8-17. 2013. http://CRAN.R-project.org/ package=dismo. Accessed on 03 July 2015.

45. Ridgeway D, and others. gbm: Generalized Boosted Regression Models. R package version 2.1.1. 2015. http://CRAN.R-project.org/package=gbm. Accessed on 03 July 2015.

46. Hijmans RJ. raster: Geographic data analysis and modeling. R package version 2.1-49. 2013. http://CRAN.R-project.org/package=raster. Accessed on 03 July 2015.

47. Bivand R, Keitt T, Rowlingson B. rgdal: Bindings for the Geospatial Data Abstraction Library. R package version 0.8-11. 2013. http://CRAN.Rproject.org/package=rgdal. Accessed on 03 July 2015

48. Urbanek S. rJava: Low-level $\mathrm{R}$ to Java interface. $\mathrm{R}$ package version 0.9-4 2013. http://CRAN.R-project.org/package=rJava. Accessed on 03 July 2015.

49. Phillips SJ, Anderson RP, Schapire RE. Maximum entropy modeling of species geographic distributions. Ecol Model. 2006;190:231-59.

50. Elith J, Leathwick JR, Hastie T. A working guide to boosted regression trees. J An Ecol. 2008;77:802-13.

51. The WorldClim - Global Climate Data. 2014. http://www.worldclim.org/ cmip5_30s/. Accessed on 03 July 2015.

52. The National Aeronautics and Space Administration (NASA) - Goddard Institute for Space Studies. 2014. http://www.giss.nasa.gov/. Accessed on 03 July 2015.

53. The European Network for Earth System Modelling - Met Office Hadley Centre. 2014. https://verc.enes.org/ models/earthsystem-models/metofficehadley-centre. Accessed on 03 July 2015.

54. Peterson AT, Ortega-Huerta MA, Bartley J, Sánchez-Cordero V, Soberón J, Buddemeier $\mathrm{RH}$, et al. Future projections for Mexican faunas under global climate change scenarios. Nature. 2002;416:626-9.

55. Dhimal M, Ahrens B, Kuch U. Species composition, seasonal occurrence, habitat preference and altitudinal distribution of malaria and other disease vectors in eastern Nepal. Parasit Vectors. 2014;7:540.

56. Gone T, Balkew M, Gebre-Michael T. Comparative entomological study on ecology and behaviour of Anopheles mosquitoes in highland and lowland localities of Derashe District, southern Ethiopia. Parasit Vectors. 2014;7:483.

57. Sinka M, Rubio-Palis Y, Manguin S, Patil AP, Temperley WH, Gething PW, et al. The dominant Anopheles vectors of human malaria in the Americas: occurrence data, distribution maps and bionomic précis. Parasit Vectors. 2010;3:72.

58. Bi Y, Yu W, Hu W, Lin H, Guo Y, Zhou XN, et al. Impact of climate variability on Plasmodium vivax and Plasmodium falciparum malaria in Yunnan Province, China. Parasit Vectors. 2013;6:357.

59. Midekisa A, Beyene B, Mihretie A, Bayabil E, Wimberly MC. Seasonal associations of climatic drivers and malaria in the highlands of Ethiopia. Parasit Vectors. 2015;8:339.

60. Roiz D, Ruiz S, Soriguer R, Figuerola J. Climatic effects on mosquito abundance in Mediterranean wetlands. Parasit Vectors. 2014;7:333.

61. Moller-Jacobs LL, Murdock CC, Thomas MB. Capacity of mosquitoes to transmit malaria depends on larval environment. Parasit Vectors. 2014;7:593.

62. Al-Amin HM, Elahi R, Mohon AN, Kafi MAH, Chakma S, Lord JS, et al. Role of underappreciated vectors in malaria transmission in an endemic region of Bangladesh-India border. Parasit Vectors. 2014;8:195. 